CANADA and the USA share in the ratio of about $2: 3$ the most extensive and one of the richest bodies of freshwater in the world-the Great Lakes system which consists of five lakes with a total surface area of 94,250 square miles. Not only are the lakes themselves large and valuable but they are surrounded by a region of gentle topography, temperate climate, vast mineral resources and bountiful farmland. Through the St Lawrence Seaway, opened in 1959, the lakes serve as a direct water link with the rest of the world, bringing ocean shipping to the heart of North America. As a result the system forms the hub of the North American population, with nearly 35 million people living in or near the Great Lakes Basin (one in every three Canadians, and one in every eight US citizens); predictions for the end of the century suggest a doubling of these figures.

When they were first discovered the vastness of the Great Lakes made them seem indestructible compared with the works of man. No longer. Their increased use, and rising industrialisation and population around their shores, makes the lakes system seem fragile in the face of man's multifarious interventions. Indeed they have proved so. Lake Erie was declared eutrophic some years ago. Both Lakes Michigan and Ontario have ceased to be safe for swimming and both have suffered serious algal blooms and fish-kills. Yet there is still a need to stretch the lakes' capacity to meet a swelling demand from the human population.

With the specific object of improving management of the Great Lakes as a whole to meet this demand, Dr D. V. Anderson, of the University of Toronto, proposed an International Field Year for the Great Lakes (IFYGL) as North America's principal contribution to the International Hydrological Decade which supposedly ends in 1975. Lake Ontario was chosen for this intensive study, because it is the smallest of the five $(7,340$ square miles) yet typical of the others (excepting Erie), convenient to study, situated in a growing population area and already showing signs of deterioration. The concept was that most of what was learned from the intensive study of Lake Ontario would be applicable to the other Great Lakes and even to other large lakes throughout the world. The project was delayed because of difficulties encountered in the USA, first in finding a 'lead' agency and then in obtaining the money for research. (Canada, with its centralised national research council structure and funding, was readily able to provide support by simply adding to ongoing projects.) The budget of $\$ 35$ million called for was eventually collected and the IFYGL was initiated in April 1972.

Curiously there had been no cooperative agreement between the USA and Canada on protective and restorative measures until that date. In the rider to the agreement then made, the point was made that although the technology for repair was adequate, solutions to many of the problems could not be prescribed because knowledge and understanding of the various interactions within the systems are "woe-

\section{Great Lakes report}

from Angela Croome

fully inadequate". Before the Field Year there had been plenty of individual scientific projects going on but there was no overall view taken. The six 'core' programmes selected-lake meteorology, energy balance, terrestrial water balance, lake water movement, biology and water chemistrywere intended to provide the data for sound solutions and wise future management. The publication of the preliminary batch of reports provides some opportunity to judge how successful this has been. Water quantity and water quality lie at the root of al the problems of the Great Lakes. The first shows up in such problems as flooding, eroding shorelines, low water in ship canals, storm damage to coasta facilities and cutbacks in production at the numerous hydroelectric plants. There is, in addition, the ice nuisance which both precludes inter-lake navigation in winter and often severely restricts the flow of water to the hydroelectric power stations. It has been suggested that waste heat from the increasing number of thermal electric stations be used to melt the ice, but this is a step to be taken only after weighing up all the other factors. Problems with water quality include sewage pollution, safe water supplies and, particularly important for Lake Ontario, the collapse of commercial fisheries. The unforeseen migration of alien species such as 'alewives' and parasitic lampreys from the Attantic up the navigation canal network has played havoc with favoured game fish though overfishing met this menace half-way.

As it happened spring 1972 to spring 1973 was atypical in one respect: the weather. It was the wettest 12 months for years. Moreover on the basis of 30 years of records the driest month of the year is usually June but in the Field Year it was the wettest (by a factor of nearly two). Not surprisingly, the inflow and outflow to the lake was also abnormal, with the July runoff four times higher than usual. Whereas pathways and balance could be studied, the normal hydrological cycle was hardly manifest. The arrival of Hurricane Agnes during some days in June however, provided a bonus in the form of a thorough check of the reliability of rainfall radars. It was found out that the radars underestimated the volume of rain by as much as $40 \%$ and the errors were particularly marked when the heaviest rain occurred. Inadequate warning of floods is attributed to the radar errors.

A special study of the lakeatmosphere boundary layer by several means was incorporated in the programme partly because of the increasing interest this interface is attracting and partly because Lake Ontario offered a convenient site on almost a 'sea' scale. Preliminary results indicate that a large fraction of the annual evaporation occurs in a very few intense, cold-air outbreaks in autumn and that on these occasions there is an extremely large gradient of evaporation across the lake. A further curiosity identified by this programme was the occurrence from time to time of a wave-driven wind on the lake. (Some wave model studies carried out in 1966 had suggested that such a phenomenon might exist.) Specific studies of airborne sulphur dioxide contamination blowing in near Niagara (calculated to amount to several tons a year) showed that a lake with a $p H$ near 8 may act as a very effective $\mathrm{SO}_{2}$ ' $\operatorname{sink}$ ' for the atmosphere.

The study of fish population, which is of major significance to the Canadian authorities as they are in the midst of attempting to restore the ravaged Lake Ontario fish stocks, was specifically aimed to be a first step in a continuing programme to guide lake management. Collections of fish were made over the whole lake in all seasons except winter. A total of 63 species was collected and produced few surprises. Samples did, however, include a few deep water sculpin (thought to have been extinct) but no examples of the equally popular indigenous cisco. Introductions, the American smelt and the alewife, dominated the main trench and were also common pelagically. The authors end their paper with a heartfelt comment that "ecology is poorly understood in the physical aquatic sciences". This work is now a continuing 'core' programme for the Canadians, who hope eventually to defeat the invading lamprey and return their lake to full health and fish production. 